\section{Association between use of cotton tipped swabs and cerumen plugs}

Cerumen plugs are common in children. They hinder the examination of children with suspected acute or chronic middle ear disease by obscuring the tympanic membrane; they also cause local skin reactions. Removal, which usually has to be done by a doctor, is mandatory, and prevention is thought to be impossible because of their unknown, possibly constitutional, nature. ${ }^{1}$ This report presents evidence of an association with the use of cotton tipped swabs.

\section{Patients, methods, and results}

One hundred and eleven children were seen for routine examinations at two child and school health clinics. Most were from skilled and semiskilled backgrounds. I defined a cerumen plug as an accumulation of wax that filled more than half the lumen of the external auditory canal. I asked mothers how they cleaned their children's ears.

Forty one children $(37 \%)$ had cerumen plugs: of these, $37(90 \%)$ had their ears cleaned by cotton tipped swab. Altogether 79 of the 111 children $(71 \%)$ had ears cleaned by cotton tipped swab, and $37(47 \%)$ of these showed plugs, as compared with four $(13 \%)$ of the remaining 32 whose ears were cleaned by other methods (flannel, finger, etc). The difference was significant $\left(\chi^{2}=11.53, p<0.001\right)$. The prevalence of plugs did not vary with age.

Fifty five mothers who used cotton tipped swabs were asked why they did so. Twenty had thought it a good idea; 11 had seen hospital midwives use them; 10 had seen them advertised; seven had family or friends who used them; one had been advised to by her doctor; and two did not know. Four had been advised against their use by midwives or health visitors. Forty four of the mothers $(80 \%)$ used cotton tipped swabs on themselves.

\section{Comment}

Cerumen plugs and the use of cotton tipped swabs are common, but a clinic population is not random. A survey of American children found $14 \%$ with ceruminosis. ${ }^{2}$ Although the strong association suggests cause and effect between plugs and the use of swabs, it does not show which is which. The hypothesis that the use of cotton tipped swabs encourages formation of plugs, and not the reverse, was supported by the observation of a clean meatus with plugs found deeper inside on examination by auriscope; in addition, many mothers, although denying "going inside," admitted to using cotton tipped swabs around the meatal orifice and used them systematically as part of the washing ritual for the reasons given above, not because the ears had plugs. Probing of the external canal with cotton tipped swabs is associated with deafness, injury, otitis externa, and "Q-tip otalgia." $3-5$

It may be possible, therefore, to reduce the prevalence of cerumen plugs by influencing the way cotton tipped swabs are used. The advice and example of midwives and health visitors are important but evidently are not always followed. It would probably be more effective to change the warnings on packets of cotton tipped swabs, which currently advise buyers against "entering" or "inserting into" the "ear canal," to one recommending that users either do not go near the ear hole or avoid the ear altogether. Additionally, doctors might find that they can avoid recurrent syringing by advising on how ears should and should not be cleaned.

I thank Dr Rosemary Graham, specialist in community medicine (child health), and Mr Mendonca, consultant ear, nose, and throat surgeon, for their advice and comments.

' Anonymous. Wax in the ear. $B r$ Med $\mathcal{F} 1972$;iv :623-4.

${ }^{2}$ Lipscomb DM. How frequent are ear lesions and hearing defects among US children? Clin Pediatr (Phila) 1973;12:125.

${ }^{3}$ Kravitz H, Neyhause AI, Dale DO, Lakur HI, Gomberg RM, Korach A. The cotton-tipped swab: a major cause of ear injury and hearing loss. Clin Pediatr (Phila) 1974;13:965-70.

${ }^{4}$ Robertson MS. The misuse of cotton wool buds. NZ Med f 1972;75:37.

${ }^{5}$ Barton RT. Q-tip otalgia. JAMA 1972;220:1619.

Richmond, Twickenham, and Roehampton Health Authority PETER BAXTER, MRCP, clinical medical officer

Correspondence to: Dr P Baxter, Royal Hospital for Sick Children, Edinburgh.

\section{Kidney transplantation and seat belt legislation}

Evidence from Australia, New Zealand, and Scandinavia has shown the effectiveness of wearing seat belts in reducing morbidity and mortality from road traffic accidents. ${ }^{1-3}$ The compulsory wearing of seat belts in the United Kingdom was approved by parliament in 1982 and became law on 1 February 1983. Shortly afterwards sensational articles appeared in several national newspapers suggesting that there would be a dramatic fall in the number of kidney donors who were casualties of road traffic accidents and that this source of cadaveric kidneys would disappear almost completely.

We carried out a study to identify the causes of death in a group of donors whose kidneys were transplanted in the period immediately before the introduction of the new seat belt legislation to assess the likely impact of the new laws on the supply of cadaveric kidneys for transplantation in the United Kingdom.

\section{Methods and results}

We investigated the causes of death of 100 consecutive donors of kidneys used for transplantation in Oxford before 1 February 1983;63 died in hospitals within the Oxford region. The remaining donors died elsewhere in the United Kingdom and their kidneys were transported to Oxford as part of the organ sharing scheme coordinated by the United Kingdom Transplant Service. The precise cause of death for each donor was obtained from the Service's donor information form supplemented when necessary by details from hospital case records. The table summarises the causes of death.

Causes of death of 100 consecutive kidney donors before 1 February 1983

\begin{tabular}{lccc}
\hline \multicolumn{1}{c}{ Cause of death } & Oxford region & $\begin{array}{c}\text { Elsewhere in } \\
\text { United Kingdom }\end{array}$ & Total \\
\hline Intracranial haemorrhage* & 23 & 12 & 35 \\
Hypoxic brain damage & 10 & 4 & 14 \\
Head injury: & 4 & 4 & 8 \\
$\quad$ Not road traffic accident & 8 & 4 & 12 \\
Pedestrian & 6 & 5 & 11 \\
Pedal cyclist & 7 & 4 & 9 \\
Motor cyclist & 5 & 37 & 100 \\
\hline Car occupant & 63 & & \\
\hline Total & & &
\end{tabular}

*Includes patients dying of spontaneous subarachnoid or intracerebral haemorrhage. +Includes patients dying of asthma, epiglottitis, croup, strangulation, cardiac arrest, and cerebellar coning.

\section{Comment}

Those caring for patients with chronic renal failure are well aware of the consequences of a sudden fall in the number of kidney donors. The Panorama television programme shown in October 1980 entitled "Transplants-are the donors really dead ?" caused a $48 \%$ reduction in transplants that took almost a year to recover, and the shortage of kidneys placed an enormous strain on dialysis facilities. Only nine of the 100 donors in this study were car drivers or passengers, two of whom were known to be wearing seat belts at the time of their accidents. Even if seat belts had saved the lives of the remaining patients there would have been only a $7 \%$ reduction in the overall number of kidneys available for transplantation in Oxford over the two years of this survey. As the proportion of donors dying as a result of car accidents in the Oxford region (7.9\%) was similar to that for donors from elsewhere in the United Kingdom $(10.8 \%)$ there is no reason to suspect any major regional variation in the proportion of patients dying in this way.

The mandatory wearing of seat belts will undoubtedly cause a shift in the pattern of injury resulting from car accidents and reduce the number of deaths, but there will still be a number of seriously injured patients who may become potential organ donors. About 8000 cadaver kidneys from around 4000 brain dead patients are potentially available for transplantation each year in the United Kingdom, ${ }^{4}$ but only about 1000 are used, so that wastage is around $88 \%$. This figure may be an underestimate as a recent survey showed that kidneys were obtained for transplantation from only 20 of 1168 patients $(1.7 \%)$ retrospectively assessed as having been potential donors. ${ }^{5}$ Thus even if a small reduction in the number of donors does occur as a result of the new seat belt laws this could easily be offset by promoting a modest increase in the rate of retrieval of organs from all the other potential donors. 